\title{
Relationship between sexual function and type 2 diabetes in infertile men referred to Royan institute
}

\author{
Zahra Jafari Torkamani $^{1}{ }^{\circledR}$, Mahrokh Dolatian $^{2^{*} \mathbb{D}}$, Reza Omani-Samani $^{3^{*}}{ }^{\circledR}$, Ahad Alizadeh $^{4^{\circledR}}$, \\ Behnaz Navid ${ }^{5}$
}

${ }^{1}$ Student Research Committee, School of Nursing and Midwifery, Shahid Beheshti University of Medical Sciences, Tehran, Iran ${ }^{2}$ Department of Midwifery and Reproductive Health, School of Nursing and Midwifery, Shahid Beheshti University of Medical Sciences, Tehran, Iran ${ }^{3}$ Department of Medical Ethics and Law, Reproductive Biomedicine Research Center, Royan Institute for Reproductive Biomedicine, Academic Center for Education, Culture, and Research (ACECR), Tehran, Iran

${ }^{4}$ Metabolic Diseases Research Center, Research Institute for Prevention of Non-Communicable Diseases, Qazvin University of Medical Sciences, Qazvin, Iran

${ }^{5}$ Reproductive Epidemiology Research Center, Royan Institute for Reproductive Biomedicine, ACECR, Tehran, Iran

\section{A R T I C L E I N F O}

Article Type:

Original

\section{Article History:}

Received: 3 June 2020

Accepted: 20 July 2020

Published online: 14 August 2020

\section{Keywords:}

Type 2 diabetes

Sexual function

Male infertility

\begin{abstract}
A B S T R A C T
Introduction: Endocrine disorders are one of the causes of infertility and sexual dysfunction is one of the neurological complications of diabetes.

Objectives: The present study investigated the relationship between sexual function and type 2 diabetes in infertile men referring to the Royan Institute in 2019.

Patients and Methods: This cross-sectional study was conducted in 2019 on 150 non-diabetic infertile men and 126 diabetic infertile men who referred to the Royan institute and were qualified in terms of research inclusion criteria. The convenience sampling method was used. The tools used to collect data include a demographic checklist, an 11-item version of Sexual Quality of Life-Male (SQOL-M), and a 15-question International Index of Erectile Function (IIEF) Questionnaire.

Results: A total of 276 people were evaluated in this study. The mean age of participants was 40.98 (7.44) years in the diabetic group and 35.2 (6.08) years in the non-diabetic group. Sexual function, failure to reach ultimate pleasure, sexual desire, satisfactory sexual intercourse, overall sexual satisfaction, erectile function, as well as the standard index of sexual quality of life (SQOL-M score) showed no statistically significant difference between diabetic and non-diabetic infertile men $(P>0.05)$. In people with normal body mass index (BMI) and employees, the relationship between diabetes and the overall score of sexual function was statistically significant $(P<0.05)$. In addition, there is a significant relationship between diabetes and the SQOL-M in people under 37 years of age and people with primary infertility $(P<0.05)$.

Conclusion: Age and BMI are the two main factors influencing sexual function. In the present study, statistical relationship of these two factors in two groups of diabetics and non-diabetic infertile men not in general but in subgroups was proved. Our investigation indicated no statistically significant relationship between the two groups of diabetic and non-diabetic infertile men in any of the factors of sexual function and the standard index of male quality of sexual life.
\end{abstract}

Implication for health policy/practice/research/medical education:

Age and body mass index influence sexual function in patients with type II diabetes. Age is unable to be controlled however weight loss can be useful to improve sexual function.

Please cite this paper as: Jafari Torkamani Z, Dolatian M, Omani-Samani R, Alizadeh A, Navid B. Relationship between sexual function and type 2 diabetes in infertile men referred to Royan institute. J Renal Inj Prev. 2021; 10(4): e33. doi: 10.34172/ jrip.2021.33.

\section{Introduction}

Infertility is defined as the failure to achieve a clinical pregnancy after 12 months or more of unprotected sex (1-3). Infertility is a prevalent phenomenon, and approximately
$10 \%-5 \%$ of couples in industrialized countries are infertile $(4,5)$. One out of seven, or roughly 49 to 72 million people worldwide, are affected by financial, psychological, and emotional stress resulting from infertility (6). About $50 \%$ 
of infertilities have male causes (6-8).

The cause of infertility can be anatomical, physiological, or genetic problems. The causes of infertility in men include testicular problems, ejaculatory duct obstruction, varicocele, male sterilization procedures, genetics, endocrine, and chromosomal problems. In men, decreased quality and volume of semen can be caused by endocrinedisrupting chemicals (9). The cause of infertility in more than half of infertile men is unknown (idiopathic) and can be congenital or acquired (10). Studies have shown that endocrine disorders are one of the leading causes of infertility (11). One of the long-term complications of diabetes is its neurological complications. Sexual dysfunction is one of the neurological complications of diabetes. Decreased libido is very common in people with diabetes, and type 2 diabetes is associated with men's reproductive health (such as hypogonadism, reduced semen quality and erectile dysfunction) $(12,13)$. In men with type 2 diabetes, erectile dysfunction is associated with depressive symptoms $(14,15)$. Men with infertility show lower secretions of sex hormone binding globulin and dehydroepiandrosterone sulfate, lower testosterone levels, and elevated cortisol and prolactin secretion. These hormonal disorders have a negative effect on the quality of semen (16). Considering significance of infertility issue and its growing prevalence among couples, and given that almost $50 \%$ of infertilities have male origins (17-21) and there are a few numbers of studies on sexual function in infertile men with the focus on their diabetes, the present study aims at investigating the relationship between sexual function and type 2 diabetes in infertile men referring to the Royan Institute in 2019.

\section{Objectives}

The present study investigated the relationship between sexual function and type 2 diabetes in infertile men referring to the Royan Institute in 2019.

\section{Patients and Methods}

\section{Study design}

This cross-sectional study was conducted in 2019 from May to July on 150 non-diabetic infertile men and 126 diabetic infertile men for two months. The convenience method was used with the following inclusion criteria; 1) diabetic and non-diabetic infertile men (based on a physician's diagnosis) referring to the Royan institute, 2) age more than 18 years, 3) ability to read, write and understand Persian. Following the description of the purpose and content of research by the researcher, participants signed the consent form, and no cost was imposed on the individuals. After explaining the purpose of the study and obtaining informed consent, the subjects entered the study voluntarily and the participants were provided with demographic checklist, 11-item version of Sexual Quality of Life-Male (SQOL-M), and 15-question International
Index of Erectile Function (IIEF) Questionnaire.

\section{Demographic checklist}

This checklist includes questions such as age, height, weight, body mass index (BMI), job, ethnicity, education, duration of marital life, family relationship with the spouse, infertility duration, number of uses of assisted reproductive technologies, previous history or present cases of relevant diseases, such as thyroid, hypertension, cardiovascular disease and kidney disease.

\section{Sexual Quality of Life-Male (SQOL-M; 11-item version item)}

This scale specifically investigates sexual quality of life in men. This questionnaire is used for the past 4 weeks to measure the quality of men's sexual life, focusing on the dimensions of sexual confidence, emotional health and interpersonal relationships. The SQOL-M consists of 11 items. The items are scored based on a 6-point Likert range from completely agree (score 1) to completely disagree (score 6) with a score range of 11-66, where a higher score implies on better quality of life (22).

\section{International Index of Erectile Function (IIEF-15)}

This tool was developed by Rosen et al in 2002 to assess sexual dysfunction in clinical trials. This questionnaire consists of 15 questions in five areas; erectile function (13-2-5-4-15), orgasmic function (9-10), sexual desire (1112), intercourse satisfaction (6-7-8), overall satisfaction (13-14). A higher score suggests a better sexual function, and the maximum acceptable score is 75 that indicates the best sexual status in various areas. The severity of sexual dysfunction is determined according to the score obtained as 0-10 (severe sexual dysfunction), 1116 (moderate), 17-21 (moderate to mild), 22-25 (mild), 26-30 (lack of sexual dysfunction). The results of the retesting of this tool (Cronbach's alpha) are in the range of 0.73-0.99 and reliability of the re-test is in the range of 0.64-0.84 (23). This questionnaire has been prepared and validated in an international study with the participation of countries from Asia, Europe, and the United States, and its sensitivity, specificity, and validity have been assessed as excellent in 10 different languages (23).

Reliability of research instrument: In this study, to determine the reliability of each instrument, the retest method was used so that each questionnaire was completed by 10 people from qualified samples of research, and then one week later, the questionnaire was completed again by the same people. Correlation between responses was measured $(\mathrm{r}=0.91)$.

\section{Statistical analysis}

Fisher's exact test and chi-square test were used to investigate the systematic relationship between the variables. Spearman correlation test was used to 
investigate the relationship between parametric (interval/ numerical) variables. Mann-Whitney $U$ test was used for measuring difference between samples. In all tests, $P$ value was considered as 0.05 .

\section{Results}

A total of 276 people were evaluated in this study. The mean age of the participants in the study was $40.98 \pm 7.44$ years in the diabetic group and $35.23 \pm 6.08$ years in the nondiabetic group. Additionally, the mean age of the spouse was 35.85 (6.14) in the diabetic group and 30.61 (5.95) in the non-diabetic group. The subject age and spouse age variables were statistically significant $(P<0.001)$.

Regarding BMI, the mean in the diabetic group was $29.39 \mathrm{~kg} / \mathrm{m}^{2}(4.93)$ and in the non-diabetic group it was $27.19 \mathrm{~kg} / \mathrm{m}^{2}(4.64)$, which is statistically significant $(P<0.001)$. Other personal information is given in Table 1. Around $16.7 \%$ in the diabetic group and $2.0 \%$ in the nondiabetic group reported a previous or current history of hypertension, which is statistically significant $(P<0.001)$.

About $51.6 \%$ of the diabetic group and $38.7 \%$ of the non-diabetic group were self-employed. Additionally, $34.1 \%$ of the diabetic group and $30.7 \%$ of the non-diabetic group were employees. Accordingly, $14.3 \%$ of the diabetic group and $30.7 \%$ of the non-diabetic group were workers, which is statistically significant $(P=0.005)$.

There was not any statistically significant difference between the two groups in terms of the frequency distribution of the variables such as infertility type, education, the spouse education, employed spouse, family relationship with the spouse, previous or current history of thyroid problems, cardiovascular problems, and kidney problems $(P>0.05)$ (Table 1$)$.

According to the findings of the IIEF-15 questionnaire, the mean and standard deviation of the total score of sexual function in the diabetic infertile men group and the non-diabetic infertile men group was 55.07 (14.09) and 56.84 (12.57), respectively.

We found no statistically significant relationship between the two groups of diabetic and non-diabetic infertile men in any of the dimensions of sexual function $(P>0.05)$.

Furthermore, the findings related to the SQOL-M questionnaire showed that the mean and standard deviation of the total score of the questionnaire in the diabetic and non-diabetic groups was 57.61 (11.09) 59.18 (10.36), respectively.

Investigations demonstrated no statistically significant relationship between the two groups of infertile diabetic and non-diabetic men in terms of male quality of sexual life $(P>0.05$; Table 2$)$.

In people with normal BMI, the mean erectile function in the diabetic and non-diabetic groups was 18.60 (5.96) and 13.17 (5.58), respectively $(P=0.001)$. In addition, in these people, the mean orgasmic function
Table 1. Personal characteristics of the studied samples

\begin{tabular}{|c|c|c|c|}
\hline \multirow[b]{2}{*}{ Variable } & \multicolumn{2}{|c|}{ Groups } & \multirow[b]{2}{*}{$P$ value } \\
\hline & $\begin{array}{l}\text { Diabetic } \\
n=(125)\end{array}$ & $\begin{array}{c}\text { Non-diabetic } \\
n=(126)\end{array}$ & \\
\hline \multicolumn{4}{|l|}{ Infertility type } \\
\hline Secondary & $34(27 \%)$ & $32(21.3 \%)$ & 0.27 \\
\hline \multicolumn{4}{|l|}{ Education } \\
\hline Illiterate & $11(8.7)$ & $11(8.7)$ & \multirow{4}{*}{0.74} \\
\hline Under diploma/diploma & $63(50.0 \%)$ & $70(46.7 \%)$ & \\
\hline A.A/Bachelor & $36(28.6 \%)$ & $52(34.7 \%)$ & \\
\hline M.A/higher & $16(12.7 \%)$ & $17(11.3 \%)$ & \\
\hline \multicolumn{4}{|l|}{ Spouse education } \\
\hline Illiterate & $5(4.0 \%)$ & $2(1.3 \%)$ & \multirow{4}{*}{0.22} \\
\hline Under diploma/diploma & $56(44.4 \%)$ & $74(49.3 \%)$ & \\
\hline A.A/Bachelor & $45(35.7 \%)$ & $59(39.3 \%)$ & \\
\hline M.A/higher & $20(15.9 \%)$ & $15(10.0 \%)$ & \\
\hline \multicolumn{4}{|l|}{ Occupation } \\
\hline Self-employed & $65(51.6 \%)$ & $58(38.7 \%)$ & \multirow{3}{*}{0.005} \\
\hline Employee & $43(34.1 \%)$ & $46(30.7 \%)$ & \\
\hline Worker & $18(14.3 \%)$ & $46(30.7 \%)$ & \\
\hline Working spouse & $31(24.6 \%)$ & $41(27.3 \%)$ & 0.60 \\
\hline Relative & $18(14.3 \%)$ & $28(18.7 \%)$ & 0.33 \\
\hline Thyroid problems & $12(9.5 \%)$ & $6(4.0 \%)$ & 0.06 \\
\hline Hypertension & $21(16.7 \%)$ & $3(2.0 \%)$ & $<0.001$ \\
\hline Cardiovascular problems & $6(4.8 \%)$ & $3(2.0 \%)$ & 0.31 \\
\hline Kidney problems & $9(7.1 \%)$ & $8(5.3 \%)$ & 0.53 \\
\hline Kidney problems & $40.98 \pm 7.44$ & $35.23 \pm 6.08$ & $<0.001$ \\
\hline Age of spouse & $35.85 \pm 6.14$ & $30.61 \pm 5.95$ & $<0.001$ \\
\hline Duration of marriage & $8.74 \pm 6.31$ & $6.77 \pm 4.04$ & 0.06 \\
\hline Duration of infertility & $6.45 \pm 5.77$ & $4.87 \pm 3.64$ & 0.107 \\
\hline Duration of diabetes & $4.29 \pm 5.07$ & 0 & $<0.001$ \\
\hline Number of treatment cycles & $1.06 \pm 1.81$ & $0.65 \pm 1.36$ & 0.008 \\
\hline $\mathrm{BMI}\left(\mathrm{kg} / \mathrm{m}^{2}\right)$ & $29.39 \pm 4.93$ & $27.19 \pm 4.64$ & $<0.001$ \\
\hline
\end{tabular}

in the diabetic and non-diabetic groups was 7.30 (2.05) and $8.19(1.47)$, respectively $(P=0.055)$. In people with normal BMI, the mean intercourse satisfaction in the diabetic and non-diabetic groups was 9.13 (4.28) and 11.30 (3.06), respectively $(P=0.03)$. In employees, there was a statistically significant relationship between the diabetic group and the IIEF-15 questionnaire $(P=0.042)$. In these individuals, the mean IIEF-total in the diabetic and non-diabetic groups was 50 (14.13) and was 58.56 (11.48), respectively. In employees, there was a statistically significant relationship between the diabetic group and the IIEF-15 questionnaire ( $P=0.003$; Table 3$)$.

In employees, the mean erectile function was 20.97 (7.16) in the diabetic group, and in the non-diabetic group it was $23.95(7.16)(P=0.026)$. In addition, the mean sexual desire of these individuals in the diabetic group 
Table 2. Mean and SD of all dimensions of IIEF-15 and SQOL-M questionnaires for men participating in the study

\begin{tabular}{|c|c|c|c|c|c|c|c|c|c|c|c|c|c|}
\hline & \multicolumn{6}{|c|}{ Non-diabetics } & \multicolumn{6}{|c|}{ Diabetics } & \multirow{2}{*}{$P$ value } \\
\hline & $\mathbf{N}$ & Mean & SD & Med & Min & Max & $\mathbf{N}$ & Mean & SD & Med & Min & Max & \\
\hline SQOL-M & 150 & 59.18 & 10.36 & 65 & 15 & 66 & 126 & 57.61 & 11.09 & 62 & 16 & 66 & 0.087 \\
\hline Erectile function & 150 & 22.43 & 6.38 & 24 & 1 & 30 & 126 & 21.50 & 6.82 & 23 & 1 & 30 & 0.273 \\
\hline Orgasmic function & 150 & 7.97 & 1.67 & 9 & 0 & 10 & 126 & 7.73 & 1.94 & 9 & 0 & 9 & 0.456 \\
\hline Sexual desire & 150 & 7.34 & 1.77 & 8 & 1 & 10 & 126 & 7.26 & 1.65 & 8 & 2 & 10 & 0.659 \\
\hline Intercourse satisfaction & 150 & 10.78 & 3.43 & 11.5 & 0 & 15 & 126 & 10.48 & 3.782 & 11 & 0 & 15 & 0.643 \\
\hline Overall satisfaction & 150 & 8.30 & 1.76 & 8 & 2 & 10 & 126 & 8.08 & 2.07 & 8 & 2 & 10 & 0.672 \\
\hline IIEF-total & 150 & 56.84 & 12.57 & 59 & 7 & 74 & 126 & 55.07 & 14.09 & 59 & 8 & 74 & 0.391 \\
\hline
\end{tabular}

was $7.51(1.40)$, and in the non-diabetic group it was 7.93 (1.87) $(P=0.06)$. In employees, the mean IIEF-total in the diabetic group was 54.51 (14.46), and in the non-diabetic group it was 60.062 (12.31). In employees, there was a statistically significant relationship between the IIEF-15 questionnaire and the diabetic group $(P=0.042$; Table 4$)$.

In people aged more than 37 years in the diabetic group, the mean SQOL-M was 56.81 (10.96) and in the nondiabetic group it was 59.42 (9.66). In people under 37 years old, there was a statistical relationship between the diabetic group and the SQOL-M $(P=0.035)$.

In people with primary infertility in the diabetic group, the mean SQOL-M was 56.89 (10.76) and in the nondiabetic group it was 59.39 (10.24). In people with primary infertility, there was a statistical relationship between the diabetic group and the SQOL-M $(P=0.029)$.

In general, the following results were obtained by performing the Mann-Whitney $U$ test in the subgroups of BMI, age, infertility type and job variables:

1. There was a statistical relationship between the diabetic group and erectile function index $(P<0.05)$ in the group with employee job (Tables 3 and 4 ).

2. There was a statistical relationship between the diabetic group and the standard index of male sexual quality of life $(\mathrm{P}<0.05)$ in individuals with a normal BMI $\left(<25 \mathrm{~kg} / \mathrm{m}^{2}\right)$ (Table 3$)$.

There was a direct and significant relationship between the SQOL-M and overall satisfaction (IIEF-total) in both diabetic and non-diabetic groups $(\mathrm{R}=0.464$ and $\mathrm{P}<0.001$ in the diabetic group and $\mathrm{R}=0.412$ and $P<0.01$ in the non-diabetic group). Investigation of the correlation coefficient of the two groups showed that there was a stronger positive correlation among non-diabetic subjects than diabetic ones (Figure 1A).

The correlation between SQOL-M and orgasmic function in the self-employed group was direct and non-significant in the diabetic group $(\mathrm{R}=0.003$ and $(P=0.991$ and in the non-diabetic group was direct and significant $(\mathrm{R}=0.318$ and $P=0.031)$. In the non-diabetic group, there was a direct and significant relationship $(\mathrm{R}=0.318$ and $P=0.031)$.

Table 3. Results of Mann-Whitney U test for BMI variable

\begin{tabular}{|c|c|c|c|c|c|c|c|c|}
\hline \multirow{2}{*}{\multicolumn{2}{|c|}{ BMI $\left(\mathrm{kg} / \mathrm{m}^{2}\right)$}} & \multicolumn{3}{|c|}{ Non-diabetic } & \multicolumn{3}{|c|}{ Diabetic } & \multirow{2}{*}{$P$ value } \\
\hline & & $\mathbf{N}$ & Mean & SD & $\mathbf{N}$ & Mean & SD & \\
\hline \multirow{6}{*}{$<25$} & SQOL-M & 46 & 60.82 & 9.26 & 23 & 54.60 & 14.98 & 0.07 \\
\hline & Erectile function & 46 & 23.17 & 5.58 & 23 & 18.60 & 5.96 & 0.001 \\
\hline & Orgasmic function & 46 & 8.19 & 1.47 & 23 & 7.30 & 2.05 & 0.055 \\
\hline & Sexual desire & 46 & 7.28 & 1.79 & 23 & 7.13 & 1.74 & 0.646 \\
\hline & Intercourse satisfaction & 46 & 11.30 & 3.06 & 23 & 9.13 & 4.28 & 0.03 \\
\hline & Overall satisfaction & 46 & 8.60 & 1.49 & 23 & 7.82 & 2.36 & 0.207 \\
\hline \multirow{8}{*}{$>25$} & IIEF-total & 46 & 58.56 & 11.48 & 23 & 50 & 14.13 & 0.003 \\
\hline & SQOL-M & 98 & 58.64 & 10.99 & 103 & 58.28 & 9.99 & 0.303 \\
\hline & Erectile function & 98 & 22.38 & 6.63 & 103 & 22.15 & 6.85 & 0.882 \\
\hline & Orgasmic function & 98 & 7.89 & 1.77 & 103 & 7.83 & 1.92 & 0.939 \\
\hline & Sexual desire & 98 & 7.39 & 1.80 & 103 & 7.29 & 1.64 & 0.625 \\
\hline & Intercourse satisfaction & 98 & 10.57 & 3.59 & 103 & 10.78 & 3.61 & 0.615 \\
\hline & Overall satisfaction & 98 & 8.20 & 1.78 & 103 & 8.13 & 2.01 & 0.778 \\
\hline & IIEF-total & 98 & 56.46 & 12.94 & 103 & 56.20 & 13.90 & 0.786 \\
\hline
\end{tabular}


Table 4. Results of the Mann-Whitney $U$ test for job variable

\begin{tabular}{|c|c|c|c|c|c|c|c|c|}
\hline \multirow{2}{*}{ Occupation } & & \multicolumn{3}{|c|}{ Non-diabetic } & \multicolumn{3}{|c|}{ Diabetic } & \multirow{2}{*}{$P$ value } \\
\hline & & $\mathbf{N}$ & Mean & SD & $\mathbf{N}$ & Mean & SD & \\
\hline \multirow{7}{*}{ Self-employed } & SQOL-M & 58 & 59.24 & 11.22 & 65 & 58.33 & 10.32 & 0.253 \\
\hline & Erectile function & 58 & 21.20 & 7.35 & 65 & 22.09 & 6.39 & 0.651 \\
\hline & Orgasmic function & 58 & 7.63 & 2.02 & 65 & 7.77 & 1.88 & 0.674 \\
\hline & Sexual desire & 58 & 6.98 & 1.73 & 65 & 7.17 & 1.71 & 0.389 \\
\hline & Intercourse satisfaction & 58 & 9.96 & 3.84 & 65 & 10.75 & 3.48 & 0.237 \\
\hline & Overall satisfaction & 58 & 8.07 & 1.92 & 65 & 8.30 & 1.88 & 0.389 \\
\hline & IIEF-Total & 58 & 53.861 & 14.34 & 65 & 56.09 & 13.21 & 0.387 \\
\hline \multirow{7}{*}{ Employee } & SQOL-M & 46 & 60.893 & 7.56 & 43 & 58.16 & 11.04 & 0.137 \\
\hline & Erectile function & 46 & 23.95 & 6.48 & 43 & 20.97 & 7.16 & 0.026 \\
\hline & Orgasmic function & 46 & 8.24 & 1.46 & 43 & 7.79 & 1.91 & 0.228 \\
\hline & Sexual desire & 46 & 7.93 & 1.87 & 43 & 7.51 & 1.40 & 0.06 \\
\hline & Intercourse satisfaction & 46 & 11.39 & 2.99 & 43 & 10.30 & 4.07 & 0.268 \\
\hline & Overall satisfaction & 46 & 8.54 & 1.60 & 43 & 7.93 & 2.13 & 0.231 \\
\hline & IIEF-Total & 46 & 60.062 & 12.31 & 43 & 54.51 & 14.46 & 0.042 \\
\hline \multirow{7}{*}{ Worker } & SQOL-M & 46 & 57.41 & 11.50 & 18 & 53.66 & 13.52 & 0.401 \\
\hline & Erectile function & 46 & 22.455 & 4.48 & 18 & 20.66 & 7.65 & 0.669 \\
\hline & Orgasmic function & 46 & 8.13 & 1.32 & 18 & 7.5 & 2.33 & 0.51 \\
\hline & Sexual desire & 46 & 7.21 & 1.61 & 18 & 7 & 2 & 0.813 \\
\hline & Intercourse satisfaction & 46 & 11.19 & 3.14 & 18 & 9.94 & 4.23 & 0.291 \\
\hline & Overall satisfaction & 46 & 8.37 & 1.71 & 18 & 7.61 & 2.57 & 0.478 \\
\hline & IIEF-Total & 46 & 57.37 & 9.43 & 18 & 52.72 & 16.61 & 0.482 \\
\hline
\end{tabular}

Examination of the correlation coefficient of the two groups showed a stronger positive correlation between diabetic subjects than non-diabetic ones (Figure 1B).

\section{Discussion}

The study was conducted in 2019 to examine the relationship between sexual function and type 2 diabetes in infertile men referred to the Royan Institute. In the present study, no significant difference in terms of sexual function between diabetic and non-diabetic infertile men was detected.

The effect and correlation of endocrine problems, such as diabetes, on nervous system disorders, especially sexual function, including erectile dysfunction and decreased libido, have been reported in other studies $(12,24)$. According to the results of statistical analysis of the IIEF questionnaire, no relationship was found between erectile function and sexual desire in two groups of the diabetic infertile men and non-diabetic infertile men. Due to the infertility of all the men in the study, infertility may have affected the results. In addition, the reason for the difference in sexual dysfunction, especially in the erection dimension, can be due to the presence of risk factors, such as cultural differences, differences in the age of the affected people and the duration of diabetes (12).

Studies have shown that poor control of diabetes, confirmed by $\mathrm{HbA} 1 \mathrm{c}$ concentrations, exacerbates erectile dysfunction in men with type 2 diabetes (12). Bak et al investigated the relationship between sexual dysfunction and depression and the acceptance of the disease by men and women with type 2 diabetes in Poland on 215 people (114 women and 101 men) with type 2 diabetes and 183 people in the control group. They used IIEF questionnaire to examine the sexual function of men. There was no association between different values of the IIEF questionnaire and blood pressure, BMI, and HbA1c variables with sexual dysfunction. However, in the present study, a statistical relationship between diabetes and the sexual function score of the IIEF questionnaire was detected.

In addition, in terms of age variable in the study of Bak et al, the age variable in the IIEF questionnaire was significant, while in the present study, the age factor in the IIEF questionnaire was insignificant. However, there was a significant relationship between diabetes and SQOL-M score in people fewer than 37 years of age. In the present study, no relationship was found between education and sexual function score, and this result is consistent with the finding by Bak et al (12).

The general attitude of men with sexual dysfunction is affected by the lack of accurate knowledge and shyness (24). Considering that the culture and cultural conditions of Iran and the Iranian people appears to be a patriarchal and religious society, and given that SQOL-M and IIEF questionnaires are about the sexual and personal issues of research subjects and answering these questionnaires can be difficult; therefore, with the help of one of the male colleagues in the institute, the researcher tried to control 
A)

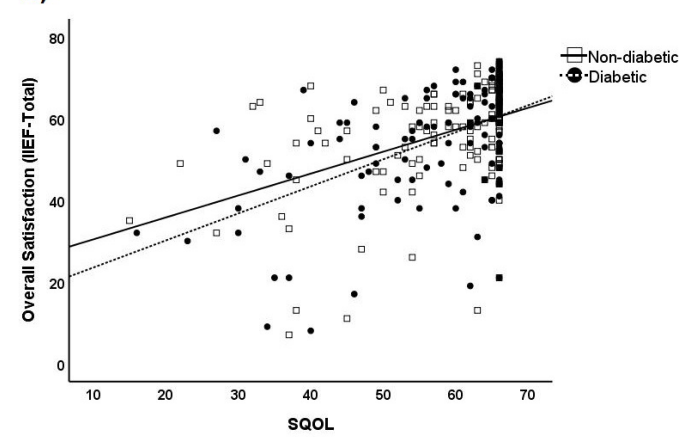

B)

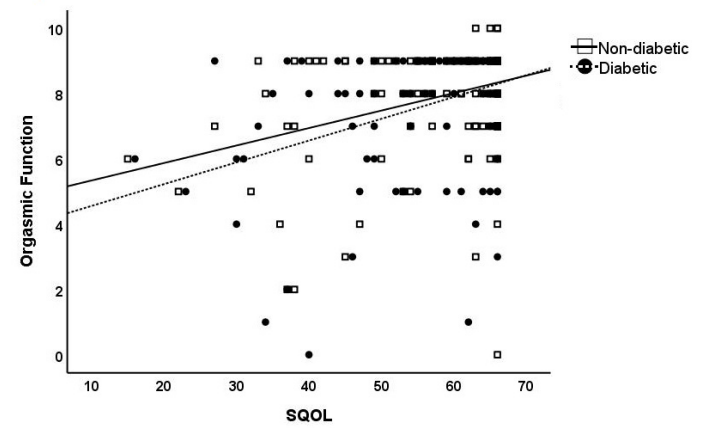

Figure 1. (A) Correlation between SQOL-M and IIEF-Total. (B) Correlation between SQOL-M and Orgasmic Function

this limitation by explaining enough about the importance of research and confidentiality of information and obtaining the satisfaction of research subjects. Moreover, the opportunity of conducting this research in one of the greatest Iranian infertility research and treatment centers is one of the strengths of the work.

\section{Conclusion}

Our investigation indicated that, overall, there is a statistical relationship between the diabetic group and IIEF score in the employee group $(P=0.042)$ in terms of subgroups of BMI, age, type of infertility and job variables. Among individuals in the age group below 37 years $(P=0.003)$ and with primary infertility $(P=0.029)$ and individuals with normal BMI $\left(<25 \mathrm{~kg} / \mathrm{m}^{2}\right)(P=0.035)$, a statistical relationship between the diabetic group and the SQOL-M score was seen. There was no significant statistical relationship between the two groups of diabetic and non-diabetic infertile men in none of different factors of sexual function $(P=0.391)$ and the standard index of quality of sexual life of men $(P=0.087)$. The results of this study can be used as basic information to explain the path of subsequent research related to male infertility.

\section{Limitations of the study}

The cross-sectional nature of the study certainly does not allow for the consideration of more factors that can affect sexual function over time. Besides, we could not draw definitive conclusions about the causal relationship between ED and SQOL-M.

\section{Acknowledgement}

The Vice-Chancellor for Research of the Shahid Beheshti University of Medical Sciences, as well as all the esteemed members of the Urology Department of the Royan Research Institute and all the professors whose valuable guidance was used in this study are highly appreciated.

\section{Authors' contribution}

ZJT, MD and ROS were the principal investigators of the study. AA, BN, ZJT, MD and ROS were included in preparing the concept and design. ZJT and MD revised the manuscript and critically evaluated the intellectual contents. All authors have read and approved the content of the manuscript and confirmed the accuracy or integrity of any part of the work.

\section{Conflicts of interest}

The authors declare that they have no competing interests.

\section{Ethical issues}

The research followed the tenets of the Declaration of Helsinki. The Ethics Committee of Shahid Beheshti University of Medical Sciences with code of IR.SBMU. RETECH.REC.1397.832 and the research project with the code of ethics of IR.ACECR, ROYAN.REC.1398.101 at Royan Institute approved this study. Accordingly, written informed consent was taken from all participants before any intervention. This study was extracted from the MSc thesis of Zahra Jafari Torkamani at this university. Moreover, ethical issues (including plagiarism, data fabrication, double publication) have been completely observed by the authors.

\section{Funding/Support}

This study was funded by Shahid Beheshti University of Medical Sciences and Royan Institute (Grant\#16387).

\section{References}

1. Zegers-Hochschild F, Adamson GD, de Mouzon J, Ishihara O, Mansour R, Nygren K, et al. International Committee for Monitoring Assisted Reproductive Technology (ICMART) and the World Health Organization (WHO) revised glossary of ART terminology, 2009. Fertil Steril. 2009;92:1520-4. doi: 10.1016/j.fertnstert.2009.09.009

2. Zegers-Hochschild F, Adamson GD, Dyer S, Racowsky C, de Mouzon J, Sokol R, et al. The international glossary on infertility and fertility care, 2017. Hum Reprod. 2017;32:1786-801. doi: 10.1093/humrep/dex234

3. Jacobson MH, Chin HB, Mertens AC, Spencer JB, Fothergill A, Howards PP. "Research on Infertility: Definition Makes 
a Difference" Revisited. Am J Epidemiol. 2018;187:337-46. doi: 10.1093/aje/kwx240.

4. Huynh T, Mollard R, Trounson A. Selected genetic factors associated with male infertility. Hum Reprod Update. 2002;8:183-98. doi: 10.1093/humupd/8.2.183

5. Sarac M, Koc I. Prevalence and risk factors of infertility in Turkey: evidence from demographic and health surveys, 1993-2013. J Biosoc Sci. 2018;50:472-90. doi: 10.1017/ s0021932017000244.

6. Öztekin Ü, Caniklioğlu M, Sarı S, Selmi V, Gürel A, Işıkay L. Evaluation of male infertility prevalence with clinical outcomes in middle Anatolian region. Cureus. 2019;11(7):e5122. doi: 10.7759/cureus.5122.

7. Tremellen K. Oxidative stress and male infertility--a clinical perspective. Hum Reprod Update. 2008;14:243-58. doi: 10.1093/humupd/dmn004.

8. Aston KI, Krausz C, Laface I, Ruiz-Castane E, Carrell DT. Evaluation of 172 candidate polymorphisms for association with oligozoospermia or azoospermia in a large cohort of men of European descent. Hum Reprod. 2010;25:1383-97. doi: 10.1093/humrep/deq081.

9. Vander Borght M, Wyns C. Fertility and infertility: Definition and epidemiology. Clin Biochem. 2018;62:2-10. doi: $\quad$ 10.1016/j.clinbiochem.2018.03.012.

10. Gupta NP, Kumar R. Lycopene therapy in idiopathic male infertility-a preliminary report. Int Urol Nephrol. 2002;34:369-72.

11. Dabbous Z, Atkin SL. Hyperprolactinaemia in male infertility: Clinical case scenarios. Arab J Urol. 2018;16:4452. doi: 10.1016/j.aju.2017.10.002.

12. Bak E, Marcisz C, Krzeminska S, Dobrzyn-Matusiak D, Foltyn A, Drosdzol-Cop A. Relationships of sexual dysfunction with depression and acceptance of illness in women and men with type 2 diabetes mellitus. Int J Environ Res Public Health. 2017;14:1073. doi: 10.3390/ ijerph 14091073.

13. Ramalho-Santos J, Amaral S, Oliveira PJ. Diabetes and the impairment of reproductive function: possible role of mitochondria and reactive oxygen species. Curr Diabetes Rev. 2008;4:46-54. doi: 10.2174/157339908783502398 .

14. Furukawa S, Sakai T, Niiya T, Miyaoka H, Miyake T, Yamamoto S, et al. Depressive symptoms and prevalence of erectile dysfunction in Japanese patients with type 2 diabetes mellitus: the Dogo Study. Int J Impot Res. 2017;29:57-60. doi: 10.1038/ijir.2016.45

15. De Berardis G, Pellegrini F, Franciosi M, Belfiglio M, Di Nardo B, Greenfield S, et al. Clinical and psychological predictors of incidence of self-reported erectile dysfunction in patients with type 2 diabetes. J Urol. 2007;177:252-7. doi: 10.1016/j.juro.2006.08.102.

16. Wdowiak A, Bien A, Iwanowicz-Palus G, MakaraStudzinska M, Bojar I. Impact of emotional disorders on semen quality in men treated for infertility. Neuro Endocrinol Lett. 2017;38:50-8. doi: 10.1111/and.12268

17. Dupree JM. Insurance coverage of male infertility: what should the standard be? Transl Androl Urol. 2018;7:S310-S6. doi: 10.21037/tau.2018.04.25.

18. Mehta A, Nangia AK, Dupree JM, Smith JF. Limitations and barriers in access to care for male factor infertility. Fertil Steril. 2016;105:1128-37. doi: 10.1016/j. fertnstert.2016.03.023.

19. Dupree JM. Insurance coverage for male infertility care in the United States. Asian J Androl. 2016;18:339-41. doi: 10.4103/1008-682X.177838.

20. Hull MG, Glazener CM, Kelly NJ, Conway DI, Foster PA, Hinton RA, et al. Population study of causes, treatment, and outcome of infertility. $\mathrm{Br}$ Med J (Clin Res Ed). 1985;291:1693-7. doi: 10.1136/bmj.291.6510.1693.

21. Vander Borght M, Wyns C. Fertility and infertility: definition and epidemiology. Clin Biochem. 2018;62:2-10. doi: 10.1016/j.clinbiochem.2018.03.012.

22. Abraham L, Symonds T, Morris MFJTjosm. Psychometric validation of a sexual quality of life questionnaire for use in men with premature ejaculation or erectile dysfunction. J Sex Med. 2008;5:595-601. doi: 10.1111/j.17436109.2007.00749.x.

23. Rosen R, Cappelleri J, Gendrano Iii N. The International Index of Erectile Function (IIEF): a state-of-the-science review. Int J Impot Res. 2002;14:226. doi: 10.1038/ sj.ijir.3900857.

24. Ansong KS, Lewis C, Jenkins P, Bell J. Help-seeking decisions among men with impotence. Urology. 1998;52:834-7. doi: 10.1016/s0090-4295(98)00397-5.

Copyright (c) 2021 The Author(s); Published by Nickan Research Institute. This is an open-access article distributed under the terms of the Creative Commons Attribution License (http://creativecommons.org/licenses/by/4.0), which permits unrestricted use, distribution, and reproduction in any medium, provided the original work is properly cited. 